\title{
Estudo de Caso da comunidade afrodescendente do município de Piracanjuba / Goiás - Brasil: Capitalismo, globalização e tradições culturais.
}

\author{
Estudio de caso de la comunidad Afrodescendiente del Municipio de \\ Piracanjuba/Goiás - Brasil: Capitalismo, globalización y tradiciones \\ culturales.
}

\author{
Case Study of the families afro-descendent from Municipality of \\ Piracanjuba / Goiás - Brazil: Capitalism, Globalization and cultural \\ traditions.
}

\author{
Iván Mauricio Perdomo Villamil ${ }^{1}$ \\ Dr. Flávio Reis dos Santos ${ }^{2}$
}

\begin{abstract}
Resumo
O principal objetivo desta proposta é desenvolver um processo de pesquisa com famílias Afrodescendentes do município de Piracanjuba / Goiás - Brasil, focando a análise sobre os impactos das políticas neoliberais associadas com o avanço da globalização em relação às práticas culturais da comunidade no atual contexto de permanente, urbanização, industrialização e tecnologização da sociedade. Entende-se que as configurações das realidades do mundo a partir da globalização, e os elementos e transformações geradas a partir deste fenômeno enfrenta as comunidades afrodescendentes a dificuldades e desafios das diversas ordens (política, econômica, social, cultural, ambiental, etc.). Esta proposta coloca-se na perspectiva de Investigação-Ação- Participativa (I.A.P.), porque além de sua flexibilidade e variedade técnica e metodológica, envolve a comunidade a participar ativamente no exercício de pesquisa, permitindo assim contribuir para o reforço do tecido social e empoderamento político, enfatizando na importância de preservar, valorizar e reconhecer a cultura Afrodescendente na região, diante os interesses econômicos e políticos do grande capital.
\end{abstract}

\footnotetext{
${ }^{1}$ Graduação em Sociología - Universidad Santo Tomás de Colombia (2005). Especialista em gestão cultural com ênfase em políticas culturais e planejamento da Universidad Nacional de Colombia. (2015). Mestrando bolsista do programa ambiente e sociedade da Universidade Estadual de Goiás. Morrinhos, Goiás. (2017). ivanpervil@gmail.com. Trabalho apresentado no I Seminário Latino-Americano de Estudos em Cultura SEMLACult, Foz do Iguaçu/PR, Brasil, 2017.

${ }^{2}$ Pós-Doutor e Doutor em Educação pela Universidade Federal de São Carlos (UFSCar). Professor e ViceCoordenador do Programa de Pós-Graduação em Ambiente e Sociedade da Universidade Estadual de Goiás (PPGAS/UEG). Coordenador do Núcleo de Estudos e Pesquisas sobre Educação Rural no Brasil. reisdossantos.flavio@gmail.com Trabalho apresentado no I Seminário Latino-Americano de Estudos em Cultura - SEMLACult, Foz do Iguaçu/PR, Brasil, 2017.
} 
Palavras-Chave: Afrodescendente; Capitalismo; Cultura ancestral; Globalização; Tradições culturais.

\begin{abstract}
Resumen
El objetivo central de esta propuesta es desarrollar un proceso de investigación con las familias afrodescendientes del municipio de Pirancanjuba /Goiás - Brasil, centrando el análisis en los impactos causados por las políticas neoliberales asociadas al avance de la globalización en relación con las practicas culturales de la comunidad en el actual contexto de permanente, urbanización, industrialización y tecnologización de la sociedad. Se entiende que las configuraciones de las realidades del mundo a partir de la globalización, los elementos y transformaciones generadas a partir de este fenómeno enfrenta las comunidades afrodescendientes a dificultades y desafíos de diversos ordenes (político, económico, social, cultural, ambiental, etc.). Esta propuesta se ubica en la perspectiva de la Investigación-Acción-Participativa (I.A.P.), ya que aparte de la flexibilidad y variedad técnica y metodológica, posibilita involucrar a la comunidad a participar activamente del ejercicio investigativo, lo que permite aportar al fortalecimiento del tejido social y empoderamiento político, enfatizando en la importancia de preservar, valorizar y reconocer la cultura afrodescendiente de la región ante los intereses económicos y políticos del grande capital.
\end{abstract}

Palabras clave: Afrodescendiente; Capitalismo; Cultura ancestral; Globalización; Tradiciones culturales.

\begin{abstract}
The main objective of this proposal is to develop a research process with the Afro-descendant families of the municipality of Pirancanjuba/Goiás - Brazil, focusing in the analysis on the impacts, caused by the neoliberal policies associated with the progress of globalization in relation to the cultural practices of the community in the current context of permanent, urbanization, industrialization and technologization of society. It is understood that the configurations of the realities of the world from the globalization, the elements and the transformations generated from this phenomenon confronts Afro-descendant communities to difficulties and challenges of the orders (political, economic, social, cultural, environmental, etc.). This proposal is located in the perspective of Investigation-Action-Participation (I.A.P), since apart from its flexibility and technical and methodological variety, the community is involved to actively participate in the investigative exercise, which makes it possible to contribute to the strengthening of the social tissue, and political empowerment, emphasizing the importance of the preservation, valuation and recognition of Afro-descendant culture of the region before the economic and political interests of big capital.
\end{abstract}

Keywords: Afro-descendant; ancestral culture; Capitalism; Cultural traditions; Globalization.

\title{
1. Introdução
}

É necessário desenvolver modelos de pesquisa que colaborem para os processos de resistência que perpassam as comunidades Afrodescendentes tanto as pertencentes quanto as não pertencentes as quilombolas do Estado de Goiás, na perspectiva de tornar possível o reconhecimento das tradições culturais e, portanto, permitir a salvaguarda da identidade de suas culturas nos dias atuais. É preciso pensar estratégias que caminhem para o fortalecimento das potencialidades locais, num mundo em que o tradicional, cada vez mais, tende a se tornar mais efêmero. A proposição desta abordagem, parte do entendimento de que a educação crítica e transformadora é a via pela qual os povos latino-americanos tem que embasar. 
Neste sentido, é indispensável o estudo de teorias e práticas de pesquisas junto com as comunidades para a criação de ferramentas destinadas à análise da realidade dos povos latino-americanos, no caso das comunidades afrodescendentes elas têm sido expostas ao longo de décadas, às injustiças das políticas econômicas e sociais do sistema capitalista, fazendo-se assim necessário o desenvolvimento de ações para que a garantia dos direitos destas populações sejam efetivadas por parte do Estado, impactando positivamente sobre as realidades enfrentadas, neste caso pelas Comunidades Quilombolas de Goiás considerando, sobretudo, a necessidade de preservação de suas culturas ancestrais.

No sistema capitalista a condição socioeconômica afeta e influencia as relações no interior da sociedade, porém há de se levar em conta que, sem exceção:

[...] todos os indivíduos estão imersos em ambientes culturais ainda que em modalidades muito desiguais de acesso pleno aos seus estoques e fluxos. Mesmo a fruição e o consumo, talvez a esfera mais larga de participação pode ser obstruída por requisitos econômicos, sociais e educacionais que limitam tal acesso. Mas de diferentes maneiras e graus todos vivem um ambiente cultural, em menor ou maior intensidade (RUBIM, 2005. p. 14).

A configuração das realidades do mundo a partir da globalização, os elementos e as transformações geradas a partir desse fenômeno em conexão com as comunidades quilombolas enfrenta dificuldades e desafios das mais diversas ordens (política, econômica, social, cultural, ambiental etc.). Perante estas situações é preciso identificar os problemas e necessidades de cada contexto, a fim de resgatar as suas tradições e promover a sustentabilidade do meio em que estão inseridas. Nesta ordem de ideias, Barbero (2002) afirma que a:

\footnotetext{
Globalização econômica e tecnológica diminui a importância do tradicional e desvaloriza referências territoriais de identidade. Afirmações contraditórias e complementares das culturas locais e regionais são reavaliadas a cada dia, exigindo maior autodeterminação, o que é um direito contar com as decisões econômicas e políticas para a construção de suas próprias imagens e a dizer-nos a sua própria história (BARBERO, 2002, p. 348 ).
}

Neste sentido, é evidente que as comunidades afrodescendentes goianas se assemelham às mais diversas comunidades étnicas latino-americanas, na medida em que estão igualmente expostas ao forte processo de vulnerabilização de seus direitos e de suas tradições culturais. Apesar da existência de algumas medidas implementadas pelo Estado, decorrência em boa parcela, da pressão de movimentos e organizações para a concretização de ações 
afirmativas para suas comunidades. Entretanto, a globalização submete as comunidades num contexto de esvaziamento das tradições culturais que tendem a evaporarem-se entre os fluxos do capital.

Ante as transformações que enfrenta a sociedade contemporânea, é essencial produzir estratégias que possibilitem às comunidades quilombolas, a preservação e proteção de suas tradições ancestrais e, neste contexto o Estado tem papel fundamental, pois é a instituição capaz de formular e implantar políticas públicas em defesa dessas populações. Touraine (2013, p. 140) afirma que se no passado recente da sociedade capitalista o Estado era responsável pela garantia de uma vida melhor para a sua população; na atualidade, alem de ter perdido um pouco de sua capacidade neste sentido, em decorrência da voracidade do processo de globalização, consegue de acordo com a "vontade de cada nação ou de cada região proteger-se contra as consequências do ininterrupto expansionismo econômico capitalista para salvaguardar o seu passado, o seu patrimônio, a sua linguagem e memória".

Diante desse cenário a pesquisa, no município de Piracanjuba/GO, intenciona-se na perspectiva de investigar os impactos causados pelas políticas neoliberais associadas ao continuum da globalização nas práticas e preservação de culturas ancestrais no atual contexto de permanente urbanização, industrialização, tecnologização da sociedade.

\section{Metodologia}

A proposta metodológica para pesquisar a influência das políticas neoliberais no contexto de globalização da sociedade contemporânea sobre os conhecimentos ancestrais das famílias afrodescendentes de Piracanjuba/GO localiza-se no emprego de uma abordagem qualitativa, orientada pelos pressupostos da Investigação-Ação-Participativa (I.A.P.).

$\mathrm{Na}$ abordagem qualitativa o investigador tem que indagar seus meios valendo-se de diversas ferramentas e técnicas para realizar o estudo, como entrevistas abertas semiestruturadas, observação participativa e grupos focais, dentre outras técnicas de coleta de informação, pois permite aprofundar no conhecimento que tem a comunidade sobre os temas abordados na pesquisa.

Este modelo de investigação é uma tradição no interior das Ciências Sociais na América Latina, conforme afirmam Ortiz e Borjas (2008):

Para iniciar é preciso recordar que entre 1960 e 1970 foi gestada na América Latina uma ampla corrente de pensamento, na qual convergiam a Educação Popular, a Teologia da Libertação, a Comunicação Alternativa, a Investigação-Ação- 
Participativa e a Filosofia da Libertação. Destes campos em convergência disciplinar intencionava-se produzir conhecimentos que permitissem aos setores subalternos da sociedade latino-americana compreender sua completa realidade a fim de transformá-la. Esta corrente de pensamento estava orientada pelo que se conhece hoje como "paradigma emancipatório", já que suas práticas tinham uma clara intencionalidade política ao fortalecer nestes grupos sociais as capacidades que gerariam transformações sociais (ORTIZ; BORJAS, 2008, p. 617) ${ }^{3}$

Orlando Fals Borda (apud MARIÑO, 2008, p.37), pioneiro e um dos precursores dessa corrente, por sua vez, argumenta que "o conhecimento empírico é conceituado pelo acadêmico, materializado, escrito e a investigação participativa se faz como renascimento com o propósito de unir o saber popular ao acadêmico"4. A associação dos diferentes segmentos, saberes populares, conhecimentos acadêmicos e ação caracterizam, de fato, as:

[...] tensões dessa corrente do pensamento latino-americano sistematizada por Fals Borda quando se faz o balanço histórico da IAP: em primeiro lugar, a tensão entre teoria e prática que conduz a um diálogo entre saberes teóricos e saberes práticos convertendo o investigador em um educador a partir do princípio freireano de "conscientização dialógica". Desta tensão se compreende "o pausado ritmo de reflexão e ação" que deve acompanhar os processos de investigação em um caminho em "espiral", segundo palavras do educador australiano Stephen Kemmis (1989) que encontrou nesta modalidade de investigação o fundamento de uma ciência social crítica bem demarcada das correntes positivistas e hermenêuticas (ORTIZ; BORJAS, 2008, p. 617) ${ }^{5}$.

\footnotetext{
${ }^{3}$ Original na Língua Espanhola: Para iniciar, es preciso recordar que entre 1960 y 1970 se fue gestando en América Latina una corriente amplia de pensamiento en la que confluyeron la Educación Popular, la Teología de la Liberación, la Comunicación Alternativa, la Investigación Acción Participativa y la Filosofía de la Liberación (Torres, 2007). Desde estos campos, en convergencia disciplinaria, se intentaba producir conocimientos que permitieran a sectores subalternos de la sociedad latinoamericana comprender su compleja realidad a fin de poderla transformar. Esta corriente de pensamiento estaba orientada por lo que hoy se conoce como el "paradigma emancipatorio", ya que sus prácticas tenían una clara intencionalidad política al fortalecer en estos grupos sociales las capacidades que generarían cambios sociales (ORTIZ; BORJAS, 2008, p. 617).

${ }^{4}$ Original na Língua Espanhola: "el académico lo que hacia era conceptualizar ese saber empírico, lo materializaba, lo escribía, la investigación participativa, como se hacia en el renacimiento , intenta juntar de esa manera el saber popular y el académico" (MARIÑO, 2008, p. 37).

${ }^{5}$ Original na Língua Espanhola: [...] tensiones de esta corriente del pensamiento latinoamericano sistematizadas por Fals Borda (2007) cuando hace el balance histórico de la IAP: en primer lugar, la tensión entre teoría y práctica que conduce a un diálogo entre saberes teóricos y saberes prácticos convirtiendo al investigador en un educador desde el principio freiriano de la "concientización dialógica". Desde esta tensión se comprende "el pausado ritmo de reflexión y acción" que debe acompañar los procesos de investigación en un camino en "espiral" según palabras del educador australiano Stephen Kemmis (1989), quien encontró en esta modalidad de investigación el fundamento de una ciencia social crítica bien demarcada de las corrientes positivistas y hermenéuticas (ORTIZ; BORJAS, 2008, p. 617).
} 
Nesse sentido, teoria e prática são indissociáveis, pois constituem duas etapas ou duas fases distintas, mas que se fundem como meio para a interpretação, como processo único e comum, contudo, "priorizando sempre a prática e colocando o conhecimento teórico a serviço do melhoramento da prática” (ORTIZ; BORJAS, 2008, p.617). Entretanto, argumentam as autoras, Orlando Fals Borda:

[...] não nega a possibilidade de que as universidades podem participar de forma direta na resolução de problemas concretos da sociedade, porém isso supõe, segundo este pesquisador colombiano, passar do conceito de "extensão universitária" ao de "universidade participante": a educação deve se fazer no pensamento e na academia, no mundo, na vida no contexto (ORTIZ; BORJAS, 2008, p. 617) ${ }^{6}$.

Fals Borda (apud ANDER-EGG, 2003, p.12) explica que as técnicas da Investigação-Ação-Participativa não dispensam o uso flexível e rápido de outras técnicas derivadas tradição das ciências sociais como os documentos escritos, a observação, os questionários, as entrevistas e infere ainda que "há um modo diferente de fazer que se traduz na prática, porém não nas técnicas próprias para a coleta de dados"7.

\section{Discussão}

Nas últimas décadas, com o vertiginoso crescimento dos avanços tecnológicos que repercutem em escala mundial com fenômenos como a globalização, tem se aprofundado a vulnerabilidade das comunidades tradicionais. É nesse contexto que se faz relevante investigar e incentivar processos que envolvem as lutas pela preservação da identidade e da culturas ancestrais para que resistam aos tempos de destruição impostos pelos modelos de desenvolvimento capitalista.

Os mais diversos grupos étnicos têm sido vítimas da destruição de sua cultura ante o frenético processo de desenvolvimento e expansionismo do capitalismo, evidenciando uma realidade em que os conhecimentos ancestrais tendem à extinção. Esses saberes tem muito valor, aliás, o valor é inestimável em nosso entendimento, pois envolve a medicina

\footnotetext{
${ }^{6}$ Original na Língua Espanhola: [...] no niega la posibilidad de que las universidades puedan participar de forma directa en la resolución de problemas concretos de la sociedad, pero eso supone, según este investigador colombiano, pasar del concepto de "extensión universitaria" al de "universidad participante": la educación debe hacerse no pensando en la academia sino en el mundo, en la vida, en el contexto (ORTIZ; BORJAS, 2008, p. 617).

${ }^{7}$ Original na Língua Espanhola: "hay un modo diferente de hacer que se traduce en la práctica, pero no en las técnicas propias para la recogida de datos".
} 
tradicional, técnicas de cultivos, língua, religião, hábitos, costumes e práticas culturais, dentre outros elementos que são singulares e caracterizam e/ou serviam para caracterizar as mais diversas comunidades, populações, sociedades no transcorrer da história da humanidade.

Entretanto, por mais intenso, mais impiedoso e mais devastador que seja o desenvolvimento do sistema econômico-produtivo capitalista, ainda existe movimentos que resistem à aculturação urbana-industrial, mantendo-se em luta pela proteção e propalação de tradições ancestrais com vistas a assegurar a preservação das identidades dos povos afrodescendentes. Nesse linha, precisamos observar de que maneira os impactos das dinâmicas do mundo globalizado afetam os contextos, as comunidades e os territórios locais acerca da manutenção da vida e da preservação dos conhecimentos ancestrais.

Os processos sociais, econômicos, políticos, ambientais e culturais das comunidades afrodescendentes no Brasil têm sido objeto de muitos estudos e pesquisas que procuram fazer um aporte teórico e prático sobre as realidades que envolvem e caracterizam estas comunidades. Contudo, é importante mencionar que são menos incidentes as aproximações e estudos sobre as condições socioeconômicas disponíveis para auxiliar e/ou garantir a existência e a preservação das culturas ancestrais em nível local.

A Academia precisa realizar mais pesquisas sobre as comunidades tradicionais brasileiras, como expressão de compromisso social com populações que de uma forma ou de outra, têm sido alvo direto e/ou indireto das politicas capitalistas neoliberais, tendo em vista desvendar e explicitar o seu verdadeiro propósito - mascarar os reais interesses do capital - e promover aproximações teórico-práticas de diferentes linhas e correntes ideológicas e investigativas, que considerem imperativas as transformações socioeconômicas e culturais de comunidades em situação de vulnerabilidade.

Nos últimos anos, as comunidades afrodescendentes têm conquistado direitos importantes em decorrência da organização e mobilização social. A luta dessas comunidades têm avançado na concretização de ações afirmativas para a satisfação de suas reivindicações e necessidades, como a propriedade da terra, o fornecimento de serviços públicos de educação, saúde, saneamento básico, transporte, reconhecimento e valorização de suas atividades produtivas artesanais, possibilitando a melhoria da qualidade de vida. Contudo, ainda há muito a ser feito, a ser assegurado pelo Estado para que o discurso de uma sociedade mais justa, inclusiva, igualitária se materialize.

\section{Conclusões}


A pesquisa encontra-se em desenvolvimento e os dados coletados até o momento são incipientes para que possamos realizar qualquer conclusão. Entretanto, em decorrência das leituras, análises, interpretações e reflexões sobre a temática central do estudo é possível afirmar que a luta pela preservação da cultura movimenta as comunidades quilombolas no resgate de suas identidades, tendo em vista a "manutenção de seus costumes de ancestralidade, religião e demais culturas consideradas legados históricos para a posteridade", na perspectiva de superar "a ideia de comunidade subalternizada, a exemplo da luta dos movimentos negros e demais instituições integradoras" (SOUSA; MOLINA, 2013, p. 14). No estágio atual de investigação, esta sendo feito o trabalho de campo (coleta de dados) na comunidade afrodescendente de Piracanjuba/GO, tendo em vista reunir as informações pertinentes mediante o emprego de técnicas metodológicas que cumprem com o rigor científico exigido pela academia, conforme foi especificado anteriormente.

\section{Referências}

ANDER-EGG, E. Repensando la investigación-acción-participativa. 4 ed. Ciudad de Mexico: Grupo Editorial Lumen, 2003. 12 p. (Obra completa )

MARIÑO, G. Encuentros y desencuentros con Orlando Fals Borda en un panel de la Universidad del Quindio. Universidad de Quindío, Armenia, 1994. 137p. (Obra completa). Disponível em: <http://www.germanmarino.com/index.php/descarga-mi-obra/investigacionap>. Acesso em: 22 jul. 2016.

MARTÍN-BARBERO,J. Oficio de Cartógrafo. Travesías latinoamericanas de la comunicación en la cultura. México: Fondo de Cultura Económica, 2002. 348 p. (Obra completa)

ORTIZ, M.; BORJA, B. La investigación acción participativa: aporte de Fals Borda a la educación popular. Espacio Abierto, Maracaibo, v. 17, n. 4, oct./dic. 2008. p.615-627. Disponível em: <http://www.redalyc.org/pdf/122/12217404.pdf >. Acesso em: 5 jul. 2016.

RUBIM, A.; RUBIM, I.; VIEIRA, M. Atores sociais, redes e políticas culturais. Universidade Federal da Bahia, Salvador, 2005. p.14. Disponível em:<http://www.cult.ufba.br/arquivos/atoressociais_redes_e_politicasculturais_catedra2005.p df>. Acesso em: 16 jul. 2016.

SOUSA, W. F.; MOLINA, R. M. A política educacional brasileira e a proposta de educação quilombola no contexto da regulação transnacional. XVI Simpósio Brasileiro da ANPAE, Recife, mai. 2013. p.1-17. Disponível em: 
<http://www.anpae.org.br/simposio26/1comunicacoes/WanildoFigueiredo-ComunicacaoOralint.pdf>. Acesso em: 14 jul. 2016.

TOURAINE, A. Después de la crisis. México/DF: Fondo de Cultura Económica, 2013. 140 p. (Obra completa) 